\title{
Loss Reduction in Distribution System Using Fuzzy Techniques
}

\author{
Sheeraz kirmani, Md. Farrukh Rahman, Chakresh Kumar \\ Department of Electrical and Electronics Engineering \\ Manav Rachna International University Faridabad India \\ Email: sheerazkirmani@gmail.com,farrukh24rahman@gmail.com,chakreshk@gmail.com
}

\begin{abstract}
In this paper, a novel approach using approximate reasoning is used to determine suitable candidate nodes in a distribution system for capacitor placement. Voltages and power loss reduction indices of distribution system nodes are modelled by furzy membership functions. A fuzzy expert system (FES) containing a set of heuristic rules is then used to determine the capacitor placement suitability of each node in the distribution system. Capacitors are placed on the nodes with the highest suitability. a new design methodology for determining the size, location, type and number of capacitors to be placed on a radial distribution system is presented. The objective is to minimize the peak power losses and the energy losses in the distribution system considering the capacitor cost. Test results have been presented along with the discussion of the algorithm.
\end{abstract}

Keywords - Capacitor placement, distribution systems, fuzzy expert system.

\section{INTRODUCTION}

Efficiency of power system depends on distribution system. Distribution system provides the final link between the high voltage transmission system and the consumers. A distribution circuit normally uses primary or main feeders and lateral distributors. The main feeder originates from the substation, and passes through the major load centers. Lateral distributors connect the individual load points to the main feeder with distribution transformers at their ends. Many distribution systems used in practice have a single circuit main feeder and are defined as radial distribution systems. Radial systems are popular because of their simple design and generally low cost [4].

Capacitor placement problem has been extensively discussed in technical literature especially since 1980's as the distribution system planning and operation started getting renewed focus. Since then, many solution techniques have been suggested identifying the problem as a complex problem of large scale mixed integer non-linear programming.

Analytical techniques [8]-[11], heuristics [12], [13], mathematical programming [6] and a host of other methods have been developed to solve the problem.

Artificial intelligent techniques have been tried in recent years in search of a superior solution tool. With rapid growth of computing power, new class of search techniques capable of handling large and complex problems has been developed during the last few decades. These techniques have also been explored for the solution of the capacitor placement problem. Among these techniques, evolutionary computing methods such as Genetic algorithm [14], [15] and Ant colony optimization [9] have been reported to produce superior results. Simulated annealing [10] and Tabu searches [11] had also been very successful. However, one common drawback of these techniques lies in the huge computing task involved in obtaining the solution On the other hand, there had always been the efforts of the system engineers to avoid applications of computation intensive complex solution processes and use simple, physically understandable logics to solve the problems, though such simplified solutions occasionally can not find the best one. Fuzzy based approaches [9]-[12] involve less computational burden.

The power loss in a distribution system is significantly high because of lower voltage and hence high current, compared to that in a high voltage transmission system [5]. The pressure of improving the overall efficiency of power delivery has forced the power utilities to reduce the loss, especially at the distribution level. In this paper a radial distribution system is taken because of its simplicity.

Fuzzy based solution methods use fuzzy membership functions to model the actual systems. Identification of proper membership function is the most challenging task in the development of fuzzy based solution techniques. Node voltage measures and power loss in the network branches have been utilized as indicators for deciding the location and also the size of the capacitors in fuzzy based capacitor placement methods.

\section{FRAME WORK OF APPROACH}

For capacitor placement, general

considerations are:

(1)the number and location;

(2) type ( fixed or switched );

(3) the size;

When capacitors are placed power loss is reduced \& also energy loss is reduced. Both these factors contribute in increasing the profit. Cost of capacitors decreases this profit. So profit is weighted against the cost of capacitor installation [1]. Whole saving can be given as follows [3].

$$
S=K_{P} \Delta P+K_{E} \Delta E-K_{C} C
$$


Where-

$\mathrm{K}_{\mathrm{P}}$-Per unit cost of peak power loss reduction $(\$ / \mathrm{KW})$

$\mathrm{K}_{\mathrm{E}-\mathrm{Per}}$ unit cost of energy loss reduction $(\$ / \mathrm{KWh})$

$\mathrm{K}_{\mathrm{C}}$-Per unit cost of capacitor ( $\left.\$ / \mathrm{KVar}\right)$

$\Delta \mathrm{p}$-Peak power loss reduction $(\mathrm{KW})$

$\Delta \mathrm{E}$-Energy loss reduction $(\mathrm{KWh})$

C-Capacitor size (KVar)

$\mathrm{S}-$ Saving in money per year (\$/year)

Then by optimising the profit ' $S$ ' due to capacitor placement actual capacitor size is determined i.e. by setting $\partial S / \partial C=0$, and then solving for $\mathrm{C}$, the capacitor size. The above procedure is repeated until no additional savings from the installation of capacitors are achieved.

For each solution voltage constraint must be satisfied. Voltage (pu) should be between min (0.9) to $\max (1.1)$.i.e.

$$
V_{\min } \leq V \leq V_{\max }
$$

In this paper shunt (fixed) capacitors are used. A simple 10 bus radial distribution system is taken as the test system. It has only main feeder \& no branches. To determine the location \& size of capacitors to be installed, a load flow program was executed on MATLAB. This gave the location of capacitor most suitable for capacitor placement. Shunt capacitors to be placed at the nodes of the system have been represented as reactive power injections [3].

\section{ALGORITHM ADOPTED FOR LOAD FLOW SOLUTION}

A balanced three-phase radial distribution network is assumed and can be represented by its equivalent single line diagram [2]. Line shunt capacitance is negligible at the distribution voltage levels. The algorithm for capacitor location finding \& sizing is as follows:

1. Perform load flow program to calculate bus voltages and segment losses.

2. Find the membership functions of voltage drops, power loss and suitability of capacitor node, and decision for the fuzzy sets of voltage drops, power loss and capacitor nodes.

3. Identify the node having highest suitability ranking.

4. Install a capacitor at optimal node (s). Select capacitor that has the lowest cost and size.

5. Check whether voltage constraint is satisfied. If yes, go to next step, otherwise, go to step- 9 .

6 . Compute the benefits due to reduction in peak power loss, energy loss and cost of capacitor banks and net savings.
7. Check whether net savings is greater than zero. If yes, go to next step, otherwise, go to step-9.

8. Increment size of capacitor bank and go to step-2.

9. Reject the installation.

Compensation of each bus' reactive power demand is done by placing capacitor. Calculation of power loss reduction \& voltage were done thereafter .Highest power loss reduction was assigned ' 1 ' \& lowest loss reduction was assigned ' 0 '. All other power loss reductions were placed between $0 \& 1$.Voltage is also given in pu values [6].

\section{CAPACITOR LOCATION FINDING USING FUZZY TECHNIQUES}

For the capacitor allocation problem, rules are defined to determine the suitability of a node for capacitor installation. Such rules are expressed in the following form:

\section{IF premise (antecedent), THEN conclusion (consequent)}

For determining the suitability of capacitor placement at a particular node, a set of multipleantecedent fuzzy rules have been established. The inputs to the rules are the voltage and power loss indices, and the output consequent is the suitability of capacitor placement. As given in table I.

The consequents of the rules are in the shaded part of the matrix. The fuzzy variables, power loss reduction, voltage, and capacitor placement suitability are described by the fuzzy terms high, highmedium/normal, medium/normal, low-medium/normal or low. These fuzzy variables described by linguistic terms are described by the fuzzy terms high, highmedium/normal, medium/normal, low-medium/normal or low [2].

These fuzzy variables described by linguistic terms are represented by membership functions. The membership functions are graphically shown in Fig. 1,2 $\&$ 3.The membership functions for describing the voltage have been created based on Ontario Hydro Standards of acceptable operating voltage ranges for distribution systems [6]. The membership functions for the PLRI and CPSI indices are created to provide a ranking. Therefore, partitions of the membership functions for the power and suitability indices are equally spaced apart.

\section{IMPLEMENTATION OF FUZZY ALGORITHM FOR CAPACITOR SIZING}

A 10 bus radial distribution feeder with $23 \mathrm{KV}$ rated voltage system is taken as the main system. $1^{\text {st }}$ bus is source bus \& other 9 buses are load bus.

TABLE I DECISION MATRIX FOR DETERMINING SUITABLE CAPACITOR LOCATION 


\begin{tabular}{|c|c|c|c|c|c|c|c|}
\hline \multicolumn{2}{|c|}{ AND } & \multicolumn{6}{|l|}{ VI } \\
\hline & & $\begin{array}{l}\text { V- } \\
\text { Low }\end{array}$ & Low & $\begin{array}{l}\text { Lo- } \\
\text { Norma } \\
1\end{array}$ & $\begin{array}{l}\text { Nor } \\
\text { mal }\end{array}$ & $\begin{array}{l}\text { Hi- } \\
\text { Norma } \\
1\end{array}$ & High \\
\hline \multirow[t]{5}{*}{$\begin{array}{l}\text { PL } \\
\text { RI }\end{array}$} & $\begin{array}{l}\text { Lo } \\
w\end{array}$ & Med & $\begin{array}{l}\text { Lo- } \\
\text { Med }\end{array}$ & $\begin{array}{l}\text { Lo- } \\
\text { Med }\end{array}$ & Low & Low & Low \\
\hline & $\begin{array}{l}\text { Lo- } \\
\mathrm{Me} \\
\mathrm{d}\end{array}$ & $\begin{array}{l}\mathrm{Hi}- \\
\text { Med }\end{array}$ & Med & $\begin{array}{l}\text { Lo- } \\
\text { Med }\end{array}$ & $\begin{array}{l}\text { Lo- } \\
\text { Med }\end{array}$ & Low & Low \\
\hline & $\begin{array}{l}\mathrm{Me} \\
\mathrm{d}\end{array}$ & High & $\begin{array}{l}\mathrm{Hi}- \\
\text { Med }\end{array}$ & Med & $\begin{array}{l}\text { Lo- } \\
\text { Med }\end{array}$ & Low & Low \\
\hline & $\begin{array}{l}\mathrm{Hi}- \\
\mathrm{Me} \\
\mathrm{d}\end{array}$ & High & $\begin{array}{l}\mathrm{Hi}- \\
\text { Med }\end{array}$ & $\begin{array}{l}\mathrm{Hi}- \\
\text { Med }\end{array}$ & Med & $\begin{array}{l}\text { Lo- } \\
\text { Med }\end{array}$ & Low \\
\hline & $\begin{array}{l}\mathrm{Hig} \\
\mathrm{h}\end{array}$ & High & High & $\begin{array}{l}\mathrm{Hi}- \\
\text { Med }\end{array}$ & Med & $\begin{array}{l}\text { Lo- } \\
\text { Med }\end{array}$ & $\begin{array}{l}\text { Lo- } \\
\text { Med }\end{array}$ \\
\hline
\end{tabular}

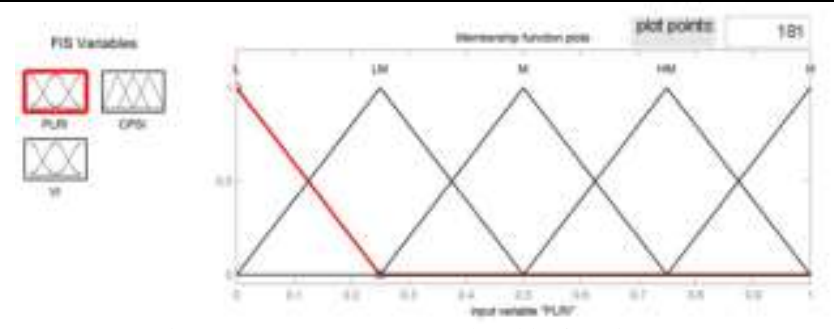

Figure1-Input 1(PLRI) membership function

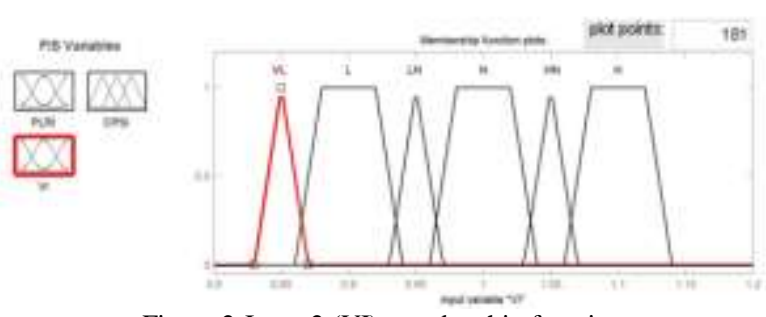

Figure 2-Input 2 (VI) membership function

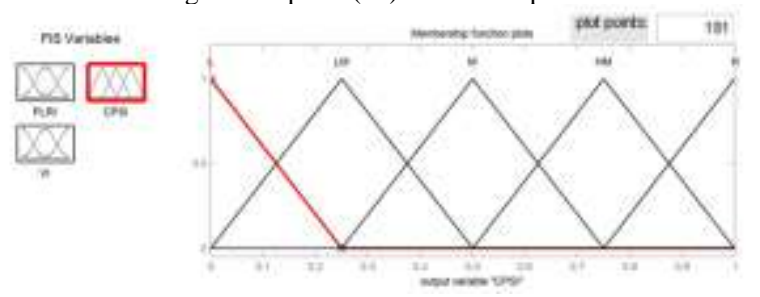

Rule base

Figure 3-Output membership (CPSI) function

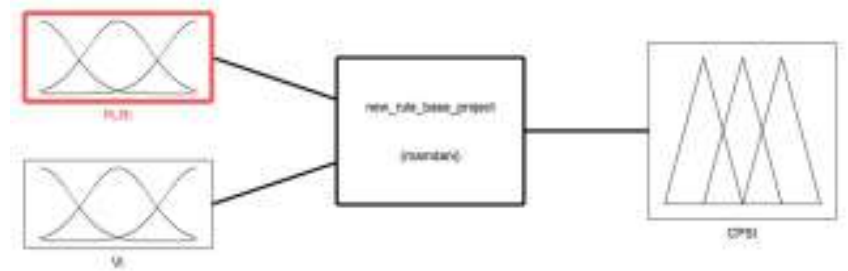

Figure 4-Rule base

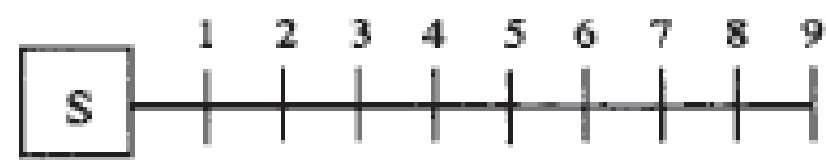

Figure 5- 10 bus radial distribution feeder

Its line data $\&$ Bus data is given in table $2 \& 3$

TABLE 2 LOAD DATA OF TEST SYSTEM

\begin{tabular}{|l|c|c|c|c|c|c|c|c|c|}
\hline Bus \# & 1 & 2 & 3 & 4 & 5 & 6 & 7 & 8 & 9 \\
\hline$P(K w)$ & 1840 & 960 & 1790 & 1598 & 1610 & 780 & 1150 & 990 & 1640 \\
\hline$Q(K v a r)$ & 460 & 340 & 446 & 1890 & 600 & 110 & 60 & 130 & 200 \\
\hline
\end{tabular}

TABLE 3 BUS DATA OF TEST SYSTEM

\begin{tabular}{|c|c|c|c|}
\hline From Bust i & To Bus: it+1 & $\mathbf{R}_{1,1+1}(n)$ & $x_{i+1}(0)$ \\
\hline 0 & I & .1233 & .4127 \\
\hline 1 & 2 & .0140 & 605 \\
\hline 2 & 3 & .746 & 12050 \\
\hline 3 & 4 & .6044 & .6084 \\
\hline 4 & 5 & 1.9401 & 1.7276 \\
\hline 5 & 6 & .053 & $-70 a b$ \\
\hline 6 & 7 & $20 \Delta s 2$ & 1.1640 \\
\hline 7 & 8 & 4785 & 27160 \\
\hline 8 & 9 & 57434 & 3.0064 \\
\hline
\end{tabular}

First bus is source bus. All the other 9 load buses were fully compensated by placing capacitors. Then power loss reduction in the entire system is calculated by load flow program using MATLAB. Both the power loss reduction index (PLRI) \& voltage sensitivity index (VI) is scaled in pu values. Based on these two values capacitor placement suitability index (CPSI) for each bus is determined by using fuzzy toolbox in MATLAB. As shown in table 4.The bus which is in urgent need of balancing will give maximum CPSI. Buses which are already balanced will give lesser values. Bus which gives highest values of CPSI is first considered for capacitor placement. Then value of capacitor to be place is determined.

TABLE 4 -BUS LOCATION FINDING FOR CAPACITOR PLACEMENT

\begin{tabular}{|l|l|l|l|}
\hline Bus & PLRI(Input 1) & VI(Input 2) & CPSI(Output) \\
\hline 1 & 0 & 0.993 & 0.08 \\
\hline 2 & 0.031 & 0.983 & 0.14 \\
\hline 3 & 0.176 & 0.960 & 0.25 \\
\hline 4 & 1 & 0.953 & 0.75 \\
\hline 5 & 0.49 & 0.918 & 0.73 \\
\hline 6 & 0.084 & 0.903 & 0.34 \\
\hline 7 & 0.039 & 0.884 & 0.30 \\
\hline 8 & 0.144 & 0.855 & 0.64 \\
\hline 9 & 0.246 & 0.837 & 0.74 \\
\hline
\end{tabular}


Bus 4 has highest CPSI, so its selected for capacitor placement. Now value of capacitor is to be found. So equation (1) was used for saving calculation.

$\mathrm{S}=\mathrm{K}_{\mathrm{P}} \Delta \mathrm{p}+\mathrm{K}_{\mathrm{E}} \Delta \mathrm{E}-\mathrm{K}_{\mathrm{C}} \mathrm{C}$

Where

$\mathrm{K}_{\mathrm{P}}=\$ 120 / \mathrm{KW}$

$\mathrm{K}_{\mathrm{E}}=\$ 0.3 / \mathrm{KWh}$

$\mathrm{K}_{\mathrm{C}}=\$ 5 / \mathrm{KVar}$

Load factor= 0.56 (Main feeder) [3].

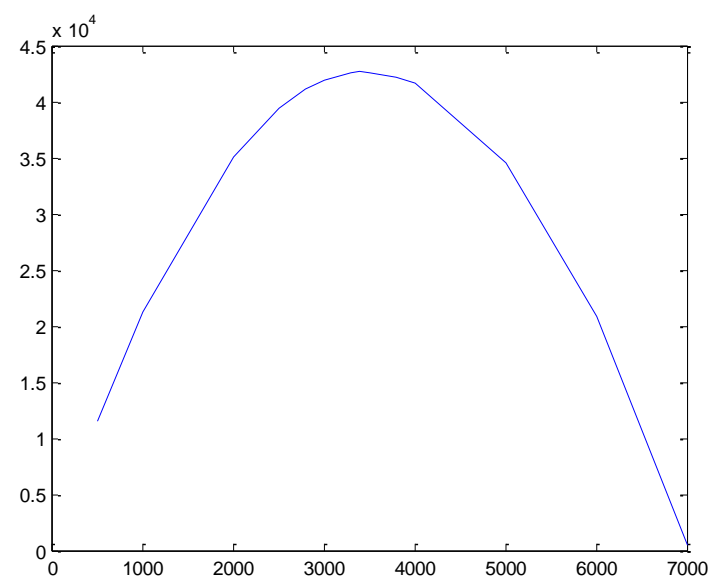

Figure 4-Curve of C Vs S for bus 4.

From load flow program on MATLAB relevant data is obtained, and a graph between $\mathrm{C} \& \mathrm{~S}$ for bus 4 is plotted. $\mathbf{S}$ is max for $\mathbf{C}=\mathbf{3 4 0 0 K V a r}$. So capacitor of this value is installed on bus 4 . After bus 4 same process is repeated. First location is determined by fuzzy techniques, then saving is calculated for different capacitor values. C-S graphs are plotted for other buses. capacitor corresponding to maximum saving is the required capacitor.

\section{Result \& discussion}

Table 5,6 \& 7 shows results after placement of capacitors.

A. Savings: As power \& energy loss is reduced and power factor improves, so there is a net benefit in installing the capacitors.

TABLE 5 CAPACITOR LOCATION, VALUE AND SAVING

\begin{tabular}{|l|l|l|l|}
\hline S. No. & $\begin{array}{l}\text { Capacitor } \\
\text { location (Bus } \\
\text { No) }\end{array}$ & $\begin{array}{l}\text { Capacitor } \\
\text { value (KVar) }\end{array}$ & Saving(\$) \\
\hline 1 & 4 & 3400 & 42650 \\
\hline 2 & 5 & 400 & 1038 \\
\hline 3 & 9 & 400 & 7036 \\
\hline Total saving & $50,724 /-$ \\
\hline
\end{tabular}

B.Voltage stabilisation: There is a considerable improvement in voltage profile after the compensation of system. It satisfies the voltage constraint.
TABLE 6 VOLTAGE IMPROVEMENT

\begin{tabular}{|l|l|l|}
\hline & $\begin{array}{l}\text { Before } \\
\text { compensation }\end{array}$ & After compensation \\
\hline $\begin{array}{l}\text { Minimum } \\
\text { voltage(pu) }\end{array}$ & 0.85 & 0.91 \\
\hline $\begin{array}{l}\text { Maximum } \\
\text { voltage(pu) }\end{array}$ & 0.990 & 0.996 \\
\hline
\end{tabular}

$C$.Power \& Energy loss reduction-As a result of capacitor placement reactive power is compensated as a result power factor of the system improves. So both energy loss \& power loss reduces. Data is obtained from load flow programme on MATLAB.

TABLE 7 POWER AND ENERGY LOSS REDUCTION

\begin{tabular}{|l|l|l|}
\hline & Before compensation & After compensation \\
\hline $\begin{array}{l}\text { Power loss } \\
(\mathrm{KW})\end{array}$ & 861.4 & 751.9 \\
\hline $\begin{array}{l}\text { Energy } \\
(\mathrm{KWh})\end{array}$ & & 214594.9 \\
\hline
\end{tabular}

\section{CONCLUSION}

An approach incorporating the use of fuzzy sets theory has been presented in this project to determine the optimal number, locations and ratings of capacitors to place in a distribution system. In choosing the ideal locations for capacitor placement, a compromise of the reactive losses and the voltage sensitivity is determined. Application of this method to a sample test system has shown its effectiveness in peak power and energy loss reductions, and improvement in voltage regulation. The same procedure with some additional considerations can be successfully applied to complex systems having sub feeders or system with more buses... In addition, this algorithm can easily he adapted for capacitor allocation in distribution system planning, expansion or operation.

\section{REFERENCES}

[1] S.K.Bhattacharya, and S.K.Goswami, "Improved Fuzzy Based Capacitor Placement Method for Radial Distribution System". IEEE Trans. Power Apparatus and Systems, vol. 108, no. 4, pp. 741-944, Apr. 2008.

[2] S. M. Kannan, Member, IEEE, A. Rathina Grace Monica, and S. Mary Raja Slochanal, "Fuzzy Logic Based Optimal Capacitor Placement on Radial Distribution Feeders IEEE Trans. on Power Apparatus and Systems, vol. 100, pp.11051118,2008 .

[3] H.N.Ng, N.M.A. Salama and .Y. Chikhani, "Capacitor allocation by Approximate reasoning fuzzy capacitor placement", IEEE Trans. Power Delivery, Vol. 15, issue. 1, P.393-398, January 2000.

[4] Hawary, "Load Flow Solution of Radial Distribution Feeders: a new contribution", International journal of Electrical Power and Energy systems, 24 (9),P.701707,Nov 2002.

[5] C.L.Wadhwa, Electrical power systems, New age international (P) limited, New Delhi, India, 2005.

[6] M. M. A. Salama, A. Y. Chikhani, R. Hackam, and E. A. A. Mansour, "Control of reactive power in distribution systems with an end-load and fixed load condition," IEEE Trans. Power 
Apparatus and Systems, vol. 104, no. 4, pp. 941-947, Apr.1995.

[7] C. Chin, W. M. Lin, "Capacitor Placements for Distribution Systems with Fuzzy Algorithm", Proceedings of the 1994 Region 10 Ninth Annual International Conference, 1994, pp$1025-1029$.

[8] Y. G. Bae, "Analytical method of capacitor allocation on distribution primary feeders", IEEE Trans. Power Apparatus and Systems, vol. 97, no. 11,pp. 1232-1238, July/Aug. 1978.

[9] J.J. Grainger, and S. H. L.ee, "Optimum Size and Location of Shunt Capacitors for Reduction of Losses on Distribution Feeders", IEEE Trans. on Power Apparatus and Systems, vol. 100, pp.1105-1118, March 1981

[10] J. J. Grainger, S. H. Lee, "Capacity Release by Shunt Capacitor Placement on Distribution Feeders: A New Voltage Dependen Model", IEEE Trans. on Power Apparatus and Systems, pp. 1236-1244, August 1982

[11] M.H. Haque, "Capacitor Placement in Radial Distribution Systems for loss Reduction", IEE Proceedings, Generation, Transmission and Distrbution, Vol. 146 issue:5, sp. 1999, pp. 501-505.

[12] S.F.Mekhamer, M.E.El-Hawary, S.A.Soliman, et.al, "New Heuristic Strategies for Reactive Power Compensation of Radial Distribution Feeders”, IEEE Transaction on Power System, Vol.17, No.43, Oct. 2002, pp. 1128-1135.

[13] Hogan, P.M.; Rettkowski, J.D.; Bala, J.L., Jr.”Optimal capacitor placement using branch and bound", Power Symposium, 2005, Proceedings of the 37th Annual North American, 23-25 Oct. 2005, pp. 84-89.

[14] G. Boone and H. D. Chiang, "Optimal capacitor placement in distribution systems by genetic algorithm", Electrical Power \& Energy Systems, vol. 15, no. 3, pp. 155-162, 1993.

[15] S. Sundhararajan and A. Pawa," Optimal Selection of Capacitor for Radial Distribution Systems using a Genetic Algorithm", IEEE Transaction on Power System, Vol.9, No. 3 Aug. 1994, pp. 1499-1507. 